\title{
A process of pair formation leading to assortative mating: passive age-assortative mating by habitat heterogeneity
}

\author{
MIGUEL FERRER \& VINCENZO PENTERIANI \\ Department of Applied Biology, Estación Bioló gica de Doñana, Consejo Superior de Investigaciones Científicas
}

\begin{abstract}
We present an individual-based model dealing with mating as a process of pair formation. Model simulations, based on data from a 19-year study of Spanish imperial eagles, Aquila adalberti, showed that the mating pattern of a population is not necessarily a direct consequence of the mating preferences of individuals; positive age-assortative mating, by which individuals of similar age are more likely to become paired, does not necessarily indicate homotypic mating preferences. For example, individuals of similar, young age may be constrained to a few low-quality territories, leading to passive assortative mating, independent of individual preferences. Confounding factors such as territory quality can affect the encounters between a male and a female available for mating, generating an age-assortative mating totally independent of mate preferences. Such a process may apply to many territorial species when spatial variation in territory quality is pronounced.
\end{abstract}

$\square 2003$ Published by Elsevier Ltd on behalf of The Association for the Study of Animal Behaviour.

A classic prediction of the theory of sexual selection is the existence of mating preferences in many bird species (e.g. Andersson 1994; Gibson \& Langen 1996). These preferences take the form of assortative mating by secondary male sexual traits (e.g. Dale \& Slagsvold 1996; Olsen et al. 1998; Wiebe 2000; Forero et al. 2001) and by age (e.g. Johnston \& Johnston 1989; Black \& Owen 1995; Potti 2000). Mate preferences based on age usually originate from positive age-assortative mating: individuals of similar age are more likely to become paired (homotypic preference). Because, generally, an adult-adult pair seems to be more productive than an immature-immature or mixed-age pair (Sæther 1990; Bradley et al. 1995), adultadult mating should be advantageous.

However, several kinds of evidence need to be considered when analysing age-assortative mating processes and patterns: (1) age-assortative mating can occur passively (reviewed in Cézilly et al. 1997; Fasola et al. 2001); (2) age-assortative mating is ambiguous, because it refers to both a pattern of pairing and the process of mate acquisition underlying the observed pattern (Burley 1983); (3) the same eventual pattern may originate from different processes or from different initial states (equifinality, Burley 1983); and (4) it is difficult to deduce the process only from knowledge of the pattern. With regard to this final point, the mating pattern of a population

Correspondence: V. Penteriani, Department of Applied Biology, Estación Biológica de Doñana, Consejo Superior de Investigaciones Científicas, Avda. de María Luisa, Pabellón del Perú, 41013 Seville, Spain (email: penteriani@ebd.csic.es). clearly depends on the mating preferences of individuals but, as emphasized by Burley (1983) and Gimelfarb (1988), the mating pattern (a population property) results from a process during which individuals attempt to realize their preferences. In theoretical works on assortative mating and sexual selection, little attention is generally given to mating as a process, and it is commonly accepted as true that an observed mating pattern is completely determined by the mating preferences of individuals, with less consideration of all the possible processes of pair formation (Gimelfarb 1988). As emphasized by Gibson \& Langen (1996), sexual selection research has been directed mainly at determining which mates are chosen and why, largely ignoring the process behind the observed pattern.

The general encounter mating model (Gimelfarb 1988) involves two stages: an encounter between a female and a male available for mating and a decision to mate or not. An encounter between two individuals of the opposite sex has to occur to initiate the male-female interaction in which the probability of pair formation will be determined by their mating preferences. A question therefore arises: how will this encounter occur? Could the manner in which the encounter happens (the first step of the mating process) represent the main determinant of the observed mating pattern?

Several studies indicate that, in heterogeneous habitats, the spatial distribution of resources affects demographic parameters and the dynamics of populations (e.g. Holt 1985; Morris 1988; Ferrer \& Donázar 1996; Delibes et al. 
2001; Penteriani et al. 2002a). The populations of territorial and solitary breeding species are often regulated through site dependence (Rodenhouse et al. 1997, 1999), that is, their breeding performance is strongly determined by the spatially heterogeneous distribution of resources within heterogeneous landscapes. If individuals of the same population inhabit territories that differ in quality, and experience habitat-specific demographic rates, then the landscape features and the distribution of individuals become major determinants of the overall population characteristics (Pulliam 1988). Therefore, social behaviour, such as mate selection, should be highly responsive to the features of heterogeneous habitats (Ostfeld et al. 1985).

In territorial birds such as raptors, territory quality is likely to differ greatly between pairs (Newton 1979, 1991; Högstedt 1980; Ferrer \& Donázar 1996; Penteriani et al. 2002a, b). Age of mates is often correlated with territory quality, with immature birds usually occupying lowquality territories (Newton et al. 1981; Steenhof et al. 1983). Furthermore, territory quality is one of the main factors affecting reproductive success, especially at the population level in high-density situations (Dhondt et al. 1992; Ferrer \& Donázar 1996). Although habitat heterogeneity in natural landscapes has often been emphasized (Wiens 1976; Turner 1989; Kotliar \& Wiens 1990; Rodenhouse et al. 1997, 1999), few studies have tested how different turnover rates between territories (e.g. mortality, migration, frequency and duration of vacancies), caused by differences in quality, could affect mating processes of populations.

In this study our main aims were (1) to investigate the age-assortative mating process in a long-lived species, the Spanish imperial eagle, Aquila adalberti, considering territory quality as a possible confounding factor affecting the mating process (i.e. the encounter of potential mates) and (2) to determine whether there is a positive assortment in mating pairs independent of mate preferences.

\section{METHODS}

\section{Study Area}

We conducted the study in Doñana National Park, southwestern Spain $\left(37^{\circ} \mathrm{N}, 6^{\circ} 30 \mid \mathrm{W}\right)$ from 1976 to 1995. Three main habitats can be distinguished in the area (Rogers \& Myers 1980): (1) Mediterranean scrubland, formed by Halimium spp., Cistus libanotis, Erica spp. with scattered cork oaks, Quercus suber, small stone pine, Pinus pinea, woods, and Eucalyptus spp. plantations; (2) marsh, mainly covered by Scirpus spp., flooded in winter and dry in summer; and (3) coastal sand dunes, with vegetation mainly made up of Ammophila arenaria, Corema album and Juniperus phoenicia. The climate is of Mediterranean type with Atlantic influence.

\section{The Species}

The Spanish imperial eagle is a large (2500-3500 g), sedentary and territorial bird of prey, with a low reproductive rate $(0.75$ chicks/pair per year), an immature period of 4-5 years, and an estimated longevity of 21-22 years (Ferrer \& Calderón 1990). Its plumage has three easily distinguishable classes: (1) juvenile, with a tawnycoloured plumage that remains until the bird is 3 years old; (2) immature, with dark patches over a tawny background colour (4-5-year-old birds); and (3) adult (>5 years), predominantly dun-coloured with characteristic white markings. This eagle is the most endangered bird of prey in Europe and one of the rarest raptors in the world (Collar \& Andrew 1988), with a total population of about 150 pairs (Ferrer 1993a). The population of the Doñana National Park consists of 15-16 breeding pairs in a highdensity situation: they occupy 20000 ha of available habitat inside the park, with a mean territory size of 1200 ha (Ferrer 1993b). The average distance between neighbouring pairs is $3.5 \mathrm{~km}$. Breeding pairs usually comprise two adults but may be mixed (one adult, one immature) or composed of two immatures (Valverde 1960; Ferrer \& Calderón 1990; Ferrer \& Bisson, in press). Territories are exclusive and vigorously defended throughout the year by the pair. In contrast, juvenile unpaired eagles are not territorial (Ferrer 1993b) and, during the dispersal period, move between temporary settling areas including the natal population area (Ferrer 1993c).

\section{Data Collection}

We used data collected between 1976 and 1995, when the population was stable (Ferrer \& Donázar 1996) and visits to nests were regular. The entire Doñana National Park area was surveyed at the beginning of each breeding season (January-February, the prelaying period) to determine whether pairs were present on territories. During the 19-year period of study, we monitored all breeding attempts $(N=237)$ and could always detect those pairs that did not attempt to breed. This allowed us to obtain precise data on the population size, the number of pairs that started reproduction and the age classes of the territorial birds.

We could delimit 16 breeding territories, defined as an area with many alternative nests, only one of which was used in any given year (Ferrer \& Donázar 1996). Analyses of reproductive output (Ferrer \& Donázar 1996) allowed us to ascertain differences in quality between territories. The first territories to be occupied in the study area were near the marsh border, which supports the highest densities of wild rabbits, Oryctolagus cuniculus, the main eagle prey (Ferrer 2001). During the last period of population increase (from 1956 to 1976), recently established pairs settled over more peripheral zones than the existing ones. Throughout the study, the mean fecundity of pairs on a territory decreased with increasing distance to optimal foraging areas (Ferrer \& Donázar 1996). We also located 44 nests and measured their distance to the marsh border.

\section{Simulation Models}

Following Reid (1988), we used individual-based models to generate the expected distribution of 
Table 1. Summary of Spanish imperial eagle mating according to age and territory in Doñana, southwestern Spain, 1976-1995

\begin{tabular}{|c|c|c|c|c|c|}
\hline \multirow[b]{2}{*}{ Territory } & \multirow[b]{2}{*}{$\begin{array}{l}\text { Total } \\
\text { pairs }\end{array}$} & \multicolumn{3}{|c|}{ Pairs } & \multirow[b]{2}{*}{$\%$ Immatures } \\
\hline & & 2 Adults & 2 Immatures & $\begin{array}{c}1 \text { Adult, } \\
1 \text { immature }\end{array}$ & \\
\hline 1 & 8 & 3 & 2 & 3 & 43.7 \\
\hline 2 & 22 & 21 & 1 & 0 & 4.5 \\
\hline 3 & 15 & 15 & 0 & 0 & 0.0 \\
\hline 4 & 14 & 9 & 0 & 5 & 17.8 \\
\hline 5 & 19 & 19 & 0 & 0 & 0.0 \\
\hline 6 & 8 & 8 & 0 & 0 & 0.0 \\
\hline 7 & 17 & 14 & 1 & 2 & 11.8 \\
\hline 8 & 4 & 1 & 3 & 0 & 75.0 \\
\hline 9 & 19 & 19 & 0 & 0 & 0.0 \\
\hline 10 & 15 & 14 & 0 & 1 & 3.3 \\
\hline 11 & 21 & 20 & 0 & 1 & 2.4 \\
\hline 12 & 17 & 14 & 0 & 3 & 8.8 \\
\hline 13 & 13 & 13 & 0 & 0 & 0.0 \\
\hline 14 & 12 & 8 & 4 & 0 & 33.3 \\
\hline 15 & 16 & 13 & 0 & 3 & 9.4 \\
\hline 16 & 17 & 17 & 0 & 0 & 0.0 \\
\hline Total & 237 & 208 & 11 & 18 & 9.2 \\
\hline
\end{tabular}

immature-immature, immature-adult and adult-adult matings, taking into account the effect of pair stability. For the first time in any study, to our knowledge, we also added the differences in territory quality as a potential factor affecting the probability of mating patterns. For these purposes, we simulated mating in a hypothetical population of 237 pairs, assuming a 0.06 yearly mortality rate, typical of the Spanish imperial eagle population of Doñana (Ferrer \& Calderón 1990).

Two models were run. In the first, we examined sensitivity of the mating distribution to changes in pair stability (the proportion of pairs with both birds surviving and that did not divorce), assuming that immature birds could potentially occupy all the territories. After each breeding season a fixed percentage of the population (94\%, i.e. 100 - the estimated mortality rate) continued to the next breeding season. Dead birds removed from the population were chosen randomly. In pairs in which both birds survived, a percentage (equal to 1-pair stability) changed mates. Birds that lost their mate, from either mortality or divorce, chose a new mate randomly from new recruits or from other experienced breeders that lost their mate, without any plumage selection. To make the simulation output comparable to the distribution that would be observed in the field data, we adjusted the number of individuals in each breeding season changing from immature to adult plumage to match the mortality of adult birds and maintain the proportion of adult/ immature individuals in the breeding population at 434/ 40 , that is, the proportion observed in our real population (Table 1).

The second model was identical to the first, but also included between-territory differences in the probability of occupancy by immature birds. We assumed that the occupancy of a territory by an immature bird was possible only if, on the basis of the real data collected in Doñana during the 19 years, more than 5\% of the immature birds occupied that territory (probability of occupancy by adults $<95 \%$ ). Consequently, not all the 16 territories had the same probability of being occupied by immature birds.

In both models, the simulation began with 237 pairs (208 adult-adult pairs, 18 immature-adult pairs and 11 immature-immature pairs; Table 1) and ran for 100 breeding seasons to allow the simulated populations to reach a stable age distribution.

All the statistical analyses were conducted with the Statgraphics (Manugistics 1992) and BMDP (Dixon \& Brown 1983) statistical packages.

\section{RESULTS}

\section{The Real Population}

During the study period there were 29 breeding attempts involving at least one immature bird, accounting for $12.2 \%$ of all breeding attempts in the park $(N=237$, Table 1$)$. Numbers of immature pairs increased to a peak in 1992. In that year, immature individuals formed $30.8 \%$ of the breeding eagles, and pairs with at least one immature bird formed $46.1 \%$ of the breeding pairs. Over 19 years, $7.2 \% \quad(N=17)$ of male mates were immature birds, and $9.9 \% \quad(N=23)$ of female mates were immature.

During the study period, immature birds never occupied six of the 16 territories, and their frequency of occupation in another three was less than 0.05. Immature individuals tended to appear more often in some territories than in others: for example, in territories 8 and 14,75 and $33 \%$, respectively, of breeding pairs were immature (Table 1). Immature breeding birds tended to be aggregated in some territories, with more than $82 \%$ of 
Table 2. Mating distribution by Spanish imperial eagles resulting from two individual-based models built under various scenarios of pair stability

\begin{tabular}{|lcccc|}
\hline $\begin{array}{l}\text { Pair } \\
\text { Stability } \\
(\%)\end{array}$ & 2 Immatures & $\begin{array}{c}\text { 1 Adult, } \\
\text { 1 immature }\end{array}$ & \\
\cline { 2 - 3 } & & 2 Adults & $P$ \\
\hline Model 1 & & & & \\
100 & 8 & 24 & 205 & 0.278 \\
95 & 6 & 28 & 203 & 0.024 \\
90 & 5 & 30 & 202 & 0.003 \\
80 & 4 & 32 & 201 & $<0.001$ \\
Model 2 & & & & \\
100 & 9 & 23 & 205 & 0.407 \\
95 & 8 & 24 & 205 & 0.278 \\
90 & 8 & 25 & 204 & 0.163 \\
80 & 7 & 26 & 204 & 0.078 \\
\hline
\end{tabular}

In Model, 1 immature birds had equal access to all territories. In Model 2, only seven territories were available to immature birds. Probabilities of no differences with respect to the observed distribution (Table 1) using chi-square tests are shown.

immature individuals in less than $44 \%$ of the territories. Differences between the observed and expected distributions, under the hypothesis of an equal probability of occupation for all the territories, were significant for immature individuals $\left(\mathrm{z}_{15}^{2}=93.497, P<0.001\right)$ as well as for pairs with at least one immature mate $\left(z_{15}^{2}=54.603\right.$, $P<0.001$ ).

Territories that were never occupied by immature breeders during the study period were closer to the marsh border $(\bar{X} \pm \mathrm{SD}=144 \pm 145.64 \mathrm{~m}, N=18)$ than those with at least one record of an immature breeder (1906士 $\left.1596.46 \mathrm{~m}, N=26 ; F_{1,42}=21.654, P<0.001\right)$.

\section{The Simulated Population}

Table 2 shows the results of the simulations. The first model, compiled assuming absence of selection by plumage and that immature individuals have access to all territories, generated a mating distribution similar to the real pattern observed in Doñana only when pair stability was $100 \%$. With values for pair stability as high as $95 \%$, significant differences were found (Table 2), with more immature-adult matings and fewer immature-immature and adult-adult matings than observed in the real data. Differences between predicted and observed mating distributions increased as pair stability decreased.

When only seven territories could be occupied by immature birds, based on the recorded percentage ( $>5 \%$ ) of immature territory occupation in Doñana, no differences between simulated and observed mating distributions were found, even for values of $80 \%$ pair stability (Model 2, Table 2). In the real data, these seven territories (43.7\% of all territories) accounted for $82.3 \%$ of all immature birds observed occupying territories.

\section{DISCUSSION}

The proportion of immature pairs found in the Spanish imperial eagle population of Doñana National Park was comparable to or higher than those described for other populations of large eagles or of other raptor species (e.g. Newton 1979; Newton et al. 1981; Steenhof et al. 1983; Pedrini \& Sergio 2001). Nevertheless, the frequency of immature raptors as breeding mates is variable and is usually associated with the rate of adult mortality (Newton 1979), as also observed in Bonelli's eagle, Hieraaetus fasciatus (Balbontín et al. 2003), peregrine falcons, Falco peregrinus (Ratcliffe 1980), and in other Spanish imperial eagle populations (Valverde 1960; Ferrer \& Calderón 1990; Ferrer 2001). Breeding by immature birds has been interpreted as the consequence of a high adult mortality rate in the population (Ferrer 2001; Balbontín et al. 2003), increasing the number of vacancies (Steenhof et al. 1983; Newton 1992).

According to some authors (Newton et al. 1981; Steenhof et al. 1983), selective mating is the result of deliberate choice. Because, generally, an adult-adult pair seems to be more productive than a mixed or immatureimmature pair, adult-adult mating should be advantageous. The observed frequency distribution of pairs could have arisen from a preference by adult birds for other adult individuals that, inevitably, resulted in a higher than expected frequency of immature-immature pairs. However, Newton et al. (1981), Village (1985) and Warkentin et al. (1992) suggested an alternative explanation for birds of prey that does not imply a deliberate choice based on higher fecundity in adult birds. Selective mating might have occurred 'passively', through immature individuals occupying certain territories more often than others. In other cases, females have been shown to choose mates deliberately on the basis of their territory quality, while ignoring male quality (e.g. Alatalo et al. 1986; Warner 1987). Such a strategy may be profitable when the direct assessment of male quality is difficult or in species in which males provide little or no parental care. In the latter case, females may fine-tune their choices on the resources defended by males, rather than on their quality (e.g. polygyny threshold model, Orians 1969). Both Potti (1998, 1999, 2000) and Bradley et al. (1995) have cast doubt on whether age-assortative matings are caused by active mate choice or by similar age-related patterns of spring migration arrivals, with individuals simply taking the next available partner. Immature birds appearing in several territories significantly more often than expected has been documented for sparrowhawks, Accipiter nisus (Newton et al. 1981), golden eagles, Aquila chrysaetos (Steenhof et al. 1983), Bonelli's eagle (Balbontín et al. 2003) and American magpie, Pica pica hudsonia (Reese \& Kadlec 1985), as well as for the colonial black-legged kittiwake, Rissa tridactyla (Wooller \& Coulson 1977). Between-territory differences in turnover rate caused by either mortality or emigration appears to be the most likely explanation for differences in the probability of occupancy by immature individuals (Steenhof et al. 1983; Ferrer 2001).

The results of our first simulation model, which included absence of selection by plumage and all territories accessible to immature birds, generated a mating distribution very similar to that observed only when pair stability was $100 \%$. According to data from other species 
of birds, values for pair stability as high as $100 \%$ seem unrealistic (Reid 1988). Consequently, we assumed that pair stability in the Spanish imperial eagle, although unknown, could be between 80 and 95\%. Using these values, the results of the first simulation differed significantly from the observed mating distribution, indicating a clear tendency to mate selectively within the two age/plumage classes.

The second simulation, which took into account the differential probability of territory occupancy by immature individuals, generated a mating distribution very similar to the observed one for all the values of pair stability simulated. We found no evidence supporting the existence of age-related assortative mating. Therefore, no assumption about age or plumage selection is needed to generate a distribution similar to the observed one. Simply considering the existence of differences between territories in the probability of occupancy by immature birds allowed us to produce the pattern observed in the Doñana population. Therefore, a direct correspondence between the pattern of individual mating preferences and the population-level mating pattern is not necessary by itself to demonstrate age-assortative mating. Our results conform to the theoretical prediction of Gimelfarb (1988) and its logical implications: (1) it is impossible to make definitive statements about mating preferences of individuals by solely observing the mating pattern of a population and vice versa (2) it is impossible to predict the mating pattern of a population from the mating preferences of its constituent individuals.

The main conclusion from our simulations is that details of the process of possible mate encounters may be important in determining the mating pattern we observe in a population. Consequently, we need to take into account the mechanisms of the male-female encounter (in our specific case determined by habitat heterogeneity, separating territories into those of high and low quality) to predict the mating patterns of a population, even if the mating preferences of the individuals are well known. In fact, our eagle population represents an example of how a population-level pattern of positive age-assortative mating does not necessarily indicate homotypic preferences at the individual level.

Unpaired immature Spanish imperial eagles spend most of their time in dispersal areas (temporary settlement areas; Ferrer 1993c, 2001), which are disjunct from breeding territories, and they occasionally visit breeding areas to check for potential vacancies. Therefore, they spend only a limited time in breeding areas. In contrast, a resident paired eagle could detect a vacancy in a highquality territory earlier than an unpaired dispersing one. This could explain why immature breeders were more frequent in territories that were far from the marsh border, which supports the highest densities of wild rabbits. Therefore, not only frequency of vacancies but also their duration could affect the probability of occupancy by immature birds, consequently determining the eventual mating pattern.

To our knowledge, this is the first evidence of ageassortative mating caused by territory quality. When we included the idea of habitat heterogeneity and the consequent existence of high- and low-quality territories, the simulated mating pattern of our hypothetical population overlapped well with the mating pattern observed in our real population. Therefore, territory quality may be a further potential factor determining a passive ageassortative mating.

Variation in the suitability of territories probably exists to some degree in most if not all natural animal populations (Rodenhouse et al. 1997; Delibes et al. 2001) and can be substantial, such as in the diverse, mosaic landscapes of Mediterranean regions. Passive age-assortative mating by habitat heterogeneity could be typical of many site-dependent populations (such as territorial raptors) characterized by pronounced gradients of territory quality (Ferrer \& Donázar 1996). In these conditions, immature birds may have an unequal probability of occupancy of different-quality territories (Pärt 2001), leading to an apparent pattern of age-assortative mating. Obviously, this pattern is clearer when density is high and gradients of territory quality are pronounced. In low-density situations or in less marked gradients of territory quality, the probability of occupancy by immature breeders could be more uniformly distributed, and the pattern of passive age-assortative mating could be less evident.

\section{Acknowledgments}

We are indebted to L. García, R. Cadenas and M. L. Chacón for help in the field. This paper has greatly benefited from conversations and comments by M. G. Forero, G. Janss, M. N. Kochert, M. Marquiss, M. T. Murphy, I. Newton, F. Sergio, J. L. Tella and A. K. Turner. FUNGESMA (Glaxo-Wellcome) and the Consejo Superior de Investigaciones Científicas (CSIC) supported this project. V.P. was supported by a European Community Marie Curie Fellowship: the author is solely responsible for information communicated and the European Commission is not responsible for any view or result expressed.

\section{References}

Alatalo, R. V., Lundberg, A. \& Glynn, C. 1986. Female pied flycatchers choose territory quality and not male characteristics. Nature, 323, 152-153.

Andersson, M. 1994. Sexual Selection. Princeton, New Jersey: Princeton University Press.

Balbontín, J., Penteriani, V. \& Ferrer, M. 2003. Variations in the age of mates as an early signal of changes in population trends: the case of Bonelli's eagle in Andalusia. Biological Conservation, 109, 417-423.

Black, J. M. \& Owen, M. 1995. Reproductive performance and assortative pairing in relation to age in barnacle geese. Journal of Animal Ecology, 64, 234-244.

Bradley, J. S., Woller, R. D. \& Skira, I. J. 1995. The relationship of pair-bond formation and duration to reproductive success in short-tailed shearwaters Puffinus tenuirostris. Journal of Animal Ecology, 64, 31-38.

Burley, N. 1983. The meaning of assortative mating. Ethology and Sociobiology, 4, 191-203. 
Cézilly, F., Boy, V., Tourenq, C. J. \& Johnson, A. R. 1997. Age-assortative pairing in the greater flamingo Phoenicopterus ruber roseus. Ibis, 139, 331-336.

Collar, N. J. \& Andrew, P. 1988. The ICBP World Checklist of Threatened Birds. Cambridge: ICBP.

Dale, S. \& Slagsvold, T. 1996. Mate choice on multiple cues, decision rules and sampling strategies in female pied flycatchers. Behaviour, 133, 903-944.

Delibes, M., Gaona, P. \& Ferreras, P. 2001. Effects of an attractive sink leading into maladaptive habitat selection. American Naturalist, 3, 277-285.

Dhondt, A. A., Kempenaers, B. \& Adriaensen, F. 1992. Densitydependent clutch size caused by habitat heterogeneity. Journal of Animal Ecology, 61, 643-648.

Dixon, W. J. \& Brown, M. J. 1983. BMDP Statistical Software. Berkeley, California: University of California Press.

Fasola, M., Zhang, Y., Zhao, D., Dong, Y. \& Wang, H. 2001. Age-assortative mating related to reproductive success in blackcrowned night herons. Waterbirds, 24, 272-276.

Ferrer, M. 1993a. El Aguila Imperial. Madrid: Editorial Quercus.

Ferrer, M. 1993b. Reduction in hunting success and settlement strategies in young Spanish imperial eagles. Animal Behaviour, 45, 406-408.

Ferrer, M. 1993c. Juvenile dispersal behaviour and natal philopatry of a long-lived raptor, the Spanish imperial eagle Aquila adalberti. Ibis, 135, 132-138.

Ferrer, M. 2001. The Spanish Imperial Eagle. Barcelona: Lynx Edicions.

Ferrer, M. \& Bisson, I. In press. Age and territory quality as factors affecting fecundity in the Spanish imperial eagle. Auk.

Ferrer, M. \& Calderón, J. 1990. The Spanish imperial eagle Aquila adalberti in Doñana National Park: a study of population dynamics. Biological Conservation, 51, 151-161.

Ferrer, M. \& Donázar, J. A. 1996. Density-dependent fecundity by habitat heterogeneity in an increasing population of Spanish imperial eagles. Ecology, 77, 69-74.

Forero, M. G., Tella, J. L., Donázar, J. A., Blanco, G., Bertellotti, M. \& Ceballos, O. 2001. Phenotypic assortative mating and withinpair sexual dimorphism and its influence on breeding success and offspring quality in Magellanic penguins. Canadian Journal of Zoology, 79, 1414-1422.

Gibson, R. M. \& Langen, T. A. 1996. How do animals choose their mates? Trends in Ecology and Evolution, 11, 468-470.

Gimelfarb, A. 1988. Processes of pair formation leading to assortative mating in biological populations: encounter-mating model. American Naturalist, 131, 865-884.

Högstedt, G. 1980. Evolution of clutch size in birds: adaptive variation in relation to territory quality. Science, 210, 1148-1150.

Holt, R. D. 1985. Population dynamics in two-patch environments: some anomalous consequences of an optimal habitat distribution. Theoretical Population Biology, 28, 181-208.

Johnston, R. F. \& Johnston, S. G. 1989. Non-random mating in feral pigeons. Condor, 91, 23-29.

Kotliar, N. B. \& Wiens, J. A. 1990. Multiple scales of patchiness and patch structure: a hierarchical framework for the study of heterogeneity. Oikos, 59, 253-260.

Manugistics 1992. Statgraphics 6.0. Statistical Graphics Systems. Rockville, Maryland: Statistical Graphics Corporation.

Morris, D. W. 1988. Habitat-dependent population regulation and community structure. Evolutionary Ecology, 2, 253-269.

Newton, I. 1979. Population Ecology of Raptors. Berkhamsted: T. \& A. D. Poyser.

Newton, I. 1991. Habitat variation and population regulation in sparrowhawks. Ibis, 133, 76-88.

Newton, I. 1992. Experiments on the limitation of bird numbers by territorial behaviour. Biological Reviews, 67, 129-173.
Newton, I., Marquiss, M. \& Moss, D. 1981. Age and breeding in sparrowhawks. Journal of Animal Ecology, 50, 839-853.

Olsen, P., Barry, S., Baker, J. B., Mooney, N., Cam, G. \& Cam, A. 1998. Assortative mating in falcons: do big females pair with big males? Journal of Avian Biology, 29, 197-200.

Orians, G. 1969. On the evolution of mating systems in birds and mammals. American Naturalist, 103, 589-603.

Ostfeld, R. S., Lidicker, W. Z. Jr \& Heske, E. J. 1985. The relationship between habitat heterogeneity, space use, and demography in a population of California voles. Oikos, 45, 433-442.

Pärt, T. 2001. Experimental evidence of environmental effects on age-specific reproductive success: the importance of resource quality. Proceedings of the Royal Society of London, Series B, 268, 2267-2271.

Pedrini, P. \& Sergio, F. 2001. Density, productivity, diet, and human persecution of golden eagles (Aquila chrysaetos) in the central-eastern Italian Alps. Journal of Raptor Research, 35, 40-48.

Penteriani, V., Gallardo, M. \& Roche, P. 2002a. Landscape structure and food supply affect eagle owl Bubo bubo density and breeding performance: a case of intra-population heterogeneity. Journal of Zoology, 257, 365-372.

Penteriani, V., Faivre, B., Mazuc, J. \& Cézilly, F. 2002b. Pre-laying vocal activity as a signal of male and nest stand quality in goshawk. Ethology, Ecology and Evolution, 14, 9-17.

Potti, J. 1998. Arrival time from spring migration in male pied flycatcher Ficedula hypoleuca: individual consistency and familial resemblance. Condor, 100, 702-708.

Potti, J. 1999. From mating to laying: genetic and environmental variation in mating dates and prelaying periods of female pied flycatchers Ficedula hypoleuca. Annales Zoologici Fennici, 36, 187194.

Potti, J. 2000. Causes and consequences of age-assortative pairing in pied flycatchers (Ficedula hypoleuca). Etología, 8, 29-36.

Pulliam, H. R. 1988. Sources, sinks, and population regulation. American Naturalist, 132, 652-661.

Ratcliffe, D. 1980. The Peregrine Falcon. Vermillion, South Dakota: Buteo Books.

Reese, K. P. \& Kadlec, J. A. 1985. Influence of high density and parental age on the habitat selection and reproduction of blackbilled magpies. Condor, 87, 96-105.

Reid, W. V. 1988. Age correlations within pairs of breeding birds. Auk, 105, 278-285.

Rodenhouse, N. L., Sherry, T. W. \& Holmes, R. T. 1997. Sitedependent regulation of population size: a new synthesis. Ecology, 78, 2025-2042.

Rodenhouse, N. L., Sherry, T. W. \& Holmes, R. T. 1999. Multiple mechanisms of population regulation: contributions of site dependence, crowding, and age structure. In: Proceedings of the 22nd International Ornithological Congress (Ed. by N. J. Adams \& R. H. Slow), pp. 2939-2952. Durban: BirdLife South Africa.

Rogers, P. M. \& Myers, K. 1980. Animal distribution, landscape classification, and wildlife management, Coto de Doñana, Spain. Journal of Applied Ecology, 17, 545-565.

Sæther, B.-E. 1990. Age-specific variation in reproductive performance of birds. Current Ornithology, 7, 251-283.

Steenhof, K., Kochert, M. N. \& Doremus, J. H. 1983. Nesting of subadult golden eagles in Southwestern Idaho. Auk, 100, 743747.

Turner, M. G. 1989. Landscape ecology: the effect of pattern on processes. Annual Review of Ecology and Systematic, 20, 171-197.

Valverde, J. A. 1960. La population d'aigles impériaux (Aquila heliaca adalberti) des marismas du Guadalquivir; son évolution depuis un siècle. Alauda, 28, 20-26.

Village, A. 1985. Spring arrival times and assortative mating of kestrels in south Scotland. Journal of Animal Ecology, 54, 857-868.

Warkentin, I. G., James, P. C. \& Oliphant, L. W. 1992. Assortative mating in urban-breeding merlins. Condor, 94, 418-426. 
Warner, R. R. 1987. Female choice of sites versus mates in a coral reef fish, Thalassoma bifasciatum. Animal Behaviour, 35, 14701478.

Wiebe, K. L. 2000. Assortative mating by color in a population of hybrid northern flickers. Auk, 117, 525-529.
Wiens, J. A. 1976. Population responses to patchy environments. Annual Review of Ecology and Systematics, 7, 81-120.

Wooller, R. D. \& Coulson, J. C. 1977. Factors affecting the age of first breeding of the kittiwake Rissa tridactyla. Ibis, 119, 339349. 